\title{
Adubos verdes e doses de nitrogênio em cobertura na cultura do trigo sob plantio direto
}

\section{Green manures and levels of nitrogen topdressing in wheat crop under no-tillage}

\author{
Anísio da Silva Nunes ${ }^{1 *}$; Luiz Carlos Ferreira de Souza²; Antonio Carlos Tadeu \\ Vitorino $^{2}$; Leandro Henrique de Souza Mota ${ }^{3}$
}

\begin{abstract}
Resumo
A adubação verde ainda é uma prática pouco utilizada na cultura do trigo, embora proporcione benefícios do ponto de vista econômico e da preservação dos recursos naturais. Este estudo foi realizado em Dourados-MS, Brasil, com o objetivo de avaliar o efeito do cultivo de crotalária (Crotalaria juncea) e ervilhaca peluda (Vicia villosa) como adubos verdes, associados a doses de nitrogênio mineral em cobertura, no desempenho agronômico do trigo em sistema plantio direto. Os tratamentos foram constituídos pelos adubos verdes, um tratamento-testemunha em pousio e seis doses de nitrogênio mineral em adubação de cobertura do trigo: zero, 30,60, 90, 120 e $150 \mathrm{~kg} \mathrm{ha}^{-1}$, utilizando-se a ureia como fonte de nitrogênio. Foram realizadas avaliações de massa seca das coberturas vegetais, teores de nitrogênio na parte aérea dos adubos verdes e nas folhas de trigo, altura de plantas, número de perfilhos produtivos, massa de mil grãos, peso hectolitro e produtividade. Verificou-se que o cultivo de adubos verdes antecedendo a semeadura do trigo promove acréscimos significativos na produtividade da cultura, especialmente quando cultivado em sucessão à crotalária. A resposta do trigo à aplicação de nitrogênio mineral variou em função da cultura antecessora.
\end{abstract}

Palavras chave: Adubação nitrogenada, crotalária, ervilhaca peluda, Triticum aestivum

\begin{abstract}
Green manure is still a not widely used practice in wheat crop, although economic benefits and conservation of natural resources can be observed due to the adoption of this practice. This study was carried out at the Dourados, Mato Grosso do Sul State, Brazil, with the objective of evaluating the effect of sunn hemp (Crotalaria juncea) and hairy vetch (Vicia villosa), associated with levels of mineral nitrogen topdressing in the agronomic performace of wheat crop under no-tillage. The treatments were constituted by green manures, fallow as a treatment-control and six doses of mineral nitrogen topdressing: zero, 30, 60, 90, 120 and $150 \mathrm{~kg} \mathrm{ha}^{-1}$. Urea was used as nitrogen source. Evaluations of dry mass of cover crops, nitrogen contents in green manures shoot and in wheat leaves, plant height, number of productive tillers per plant, one thousand-grains weight, hectolitric weight and yield were made. It was concluded that the use of green manures before wheat seeding promotes significant increases in crop yield, mainly when planted over to sunn hemp. The wheat yield response to mineral nitrogen application varied according to the preceding crop.
\end{abstract}

Key words: Fertilization, sunn hemp, hairy vetch, Triticum aestivum

\footnotetext{
1 Eng $^{\mathrm{o}} \mathrm{Agr}^{\mathrm{o}}$, MSc. Universidade Federal da Grande Dourados, UFGD Faculdade de Ciências Agrárias Rodovia Dourados à Itahum, km 12 - Caixa Postal 533 CEP 79804-970. Dourados, MS. E-mail: anisionunes@yahoo.com.br

2 Profs. Drs. da Universidade Federal da Grande Dourados, UFGD E-mail: luizsouza@ufgd.edu.br; antoniovitorino@ufgd.edu.br

3 Eng $^{\mathrm{o}} \mathrm{Agr}^{\circ}$, Universidade Federal da Grande Dourados, UFGD Faculdade de Ciências Agrárias Rodovia Dourados à Itahum, km 12 - Caixa Postal 533 CEP 79804-970. Dourados, MS. E-mail:1eandromota22@bol.com.br
}

*Autor para correspondência

Recebido para publicação 07/05/2010 Aprovado em 13/04/2011 


\section{Introdução}

Dentre as práticas de manejo disponíveis para a cultura do trigo, a adubação verde destaca-se por melhorar os atributos químicos, físicos e biológicos do solo, a baixo custo. Seus múltiplos efeitos têm sido constatados na proteção do solo, na elevação dos teores de matéria orgânica, no aumento da capacidade de troca catiônica e da ciclagem dos nutrientes das camadas mais profundas para a superfície (AMABILE; FANCELLI; CARVALHO, 2000). Muitos autores têm confirmado o aporte de nitrogênio proveniente do processo biológico promovido por bactérias diazotróficas e promotoras do crescimento vegetal, com o cultivo de leguminosas antecedendo as culturas econômicas (AMADO; MIELNICZUK; FERNANDES, 2000; AITA et al., 2001; SILVA et al., 2008; MARRERO et al., 2009).

A adubação verde é uma prática agrícola conhecida desde antes da era Cristã, por gregos, romanos e chineses e seus benefícios são amplamente conhecidos e divulgados (SANTOS et al., 2006). Entretanto, esta prática ainda é pouco utilizada pelos agricultores brasileiros, sobretudo na cultura no trigo, por uma série de razões, que vão desde motivos de cunho comercial, como o intenso trabalho de marketing das empresas de fertilizantes minerais, até dificuldades técnicas, como o intervalo restrito de tempo para o cultivo do adubo verde entre a colheita da safra de verão e a semeadura do trigo.

As inúmeras espécies de plantas utilizadas como adubos verdes proporcionam efeito residual variável, sugerindo assim que sejam usadas aquelas com maior potencialidade em relação ao aumento da produtividade das culturas econômicas (AITA et al., 2001), tendo em vista que a quantidade real de nutrientes que será aproveitada pela cultura em sucessão irá depender não só da capacidade de acúmulo e ciclagem de nutrientes, como também do sincronismo entre a decomposição da biomassa e os estágios de maior demanda da cultura (BREDEMEIER; MUNDSTOCK, 2001).
Uma parte significativa do nitrogênio aplicado como fertilizante é perdido por lixiviação, desnitrificação e volatilização. O grande desafio no manejo deste nutriente, portanto, é aumentar a quantidade absorvida pelas plantas e diminuir, ao mesmo tempo, as perdas ocorridas. Em estudos sobre o balanço do nitrogênio na cultura do trigo, com uso da técnica isotópica, observou-se que, quando o manejo da adubação é bem realizado, de $90 \mathrm{~kg}$ de ureia aplicados, $57 \mathrm{~kg}$ ficaram acumulados nos grãos (65\%), sendo exportados com a colheita; $15 \mathrm{~kg}$ ficaram no solo; $15 \mathrm{~kg}$ permaneceram na palha do trigo, podendo ser aproveitado no sistema, caso a palha permaneça no campo; $1 \mathrm{~kg}$ foi encontrado nas raízes e $1 \mathrm{~kg}$ foi lixiviado abaixo de $50 \mathrm{~cm}$ de profundidade (BOLOGNA et al., 2006).

Materiais orgânicos são fontes importantes de nitrogênio na produção agrícola, tanto em pequenas propriedades (HOOD, 2001) quanto na agricultura empresarial em grande escala, e a integração de fertilizantes minerais e orgânicos pode ser uma estratégia para incrementar a produtividade das culturas. Arf et al. (1999) destacaram que o uso combinado de fertilizantes minerais e de adubos verdes constitui uma importante prática de manejo, por meio da qual se procura preservar os agroecossistemas, além de aumentar a produtividade agrícola. Araújo et al. (2005) avaliaram o efeito de adubos verdes e doses de ureia na recuperação de ${ }^{15} \mathrm{~N}$-ureia aplicado na cultura do trigo e obtiveram maiores recuperações do ${ }^{15} \mathrm{~N}$-ureia pela cultura no manejo conjunto de ureia e crotalária, devido à maior disponibilidade de nitrogênio no solo, que proporcionou o estreitamento da relação $\mathrm{C} / \mathrm{N}$ do adubo verde, favorecendo a mineralização do nitrogênio.

Nesse sentido, objetivou-se neste trabalho avaliar o efeito dos adubos verdes crotalária e ervilhaca peluda, associadas a doses de nitrogênio em adubação de cobertura, no desempenho agronômico da cultura do trigo em sistema plantio direto. 


\section{Material e Métodos}

O trabalho foi realizado em Dourados - MS, Brasil, situado a $22^{\circ} 13^{\prime} 16^{\prime \prime}$ de latitude Sul, $54^{\circ} 17^{\prime}$ $01^{\prime}$ de longitude Oeste e altitude de 430 metros. O solo da área experimental foi classificado como
Latossolo Vermelho Distroférrico (EMBRAPA, 2006), originalmente sob vegetação de Cerrado. Os resultados da análise química do solo, realizada antes da semeadura dos adubos verdes, em cinco profundidades, são apresentados na (Tabela 1).

Tabela 1. Valores médios ${ }^{(1)}$ da análise química do solo realizada antes da semeadura dos adubos verdes na área experimental. Dourados - MS, 2007.

\begin{tabular}{lccccccccccc}
\hline $\begin{array}{l}\text { Profundidades } \mathbf{M . O} . \\
(\mathbf{c m})\end{array}$ & $\mathbf{p H}$ & $\mathbf{P}^{(2)}$ & $\mathbf{K}$ & $\mathbf{A l}$ & $\mathbf{C a}$ & $\mathbf{M g}$ & $\mathbf{H}+\mathbf{A l}$ & $\mathbf{S B}$ & $\mathbf{T}$ & $\mathbf{V}$ \\
\hline $0-2,5$ & 32,8 & 5,2 & 18 & 8,8 & 0,0 & 43,0 & 21,0 & 36,0 & 72,8 & 108,8 & 66 \\
$2,5-5,0$ & 27,4 & 5,0 & 18 & 5,1 & 0,6 & 43,0 & 16,0 & 47,0 & 64,1 & 111,1 & 57 \\
$5,0-10,0$ & 25,2 & 4,9 & 13 & 4,9 & 0,6 & 42,0 & 11,0 & 47,0 & 57,9 & 104,9 & 55 \\
$10,0-20,0$ & 24,6 & 5,0 & 7 & 4,4 & 0,6 & 39,0 & 10,0 & 40,0 & 53,4 & 93,4 & 57 \\
$20,0-40,0$ & 17,8 & 5,2 & 2 & 1,6 & 0,0 & 29,0 & 7,0 & 36,0 & 37,6 & 73,6 & 51 \\
\hline
\end{tabular}

${ }^{(1)}$ Determinações segundo Claessen (1997). ${ }^{(2)}$ P-resina.

O delineamento experimental utilizado foi o de blocos casualizados, com os tratamentos dispostos em um esquema de parcelas subdivididas, com quatro repetições. As parcelas, de dimensões $35 \mathrm{~m}$ x $9 \mathrm{~m}$, foram constituídas pelos adubos verdes: ervilhaca peluda (Vicia villosa Hoth), crotalária (Crotalaria juncea L.) e um tratamento-testemunha, sem o cultivo de adubos verdes. Nas subparcelas, de dimensões 8 $\mathrm{m} \times 1,5 \mathrm{~m}$, foram testadas seis doses de nitrogênio mineral em adubação de cobertura na cultura do trigo (zero, 30, 60, 90, 120 e $150 \mathrm{~kg} \mathrm{ha}^{-1}$ de nitrogênio).

Os adubos verdes foram semeados mecanicamente em sucessão à cultura do milho, na primeira quinzena de fevereiro e manejados 75 dias após sua semeadura, por meio de um triturador modelo Triton $^{\odot}$. Antes do manejo dos adubos verdes, determinou-se a produção de massa seca dos mesmos e da vegetação espontânea presente nas parcelas em pousio, bem como os teores de nitrogênio na parte área dos adubos verdes, por meio da amostragem com um quadro de $0,25 \mathrm{~m}^{2}$ lançado aleatoriamente nas parcelas, com oito amostras por parcela. As plantas foram cortadas rente ao solo, lavadas e secas em estufa com circulação forçada de ar a $65{ }^{\circ} \mathrm{C}$, até peso constante. Após a secagem, o material amostrado foi moído e levado ao laboratório para determinação dos teores de nitrogênio na parte aérea dos adubos verdes, pelo método de Kjeldahl (MALAVOLTA; VITTI; OLIVEIRA, 1997). O nitrogênio acumulado na parte aérea dos adubos verdes foi calculado por meio da multiplicação dos valores de produção de massa seca pelos seus respectivos teores de nitrogênio.

Antes da semeadura do trigo, foi aplicado o herbicida glyphosate, na dosagem de 2,4 $\mathrm{L} \mathrm{ha}^{-1}$ em toda área experimental para o controle das plantas daninhas remanescentes. O trigo foi semeado mecanicamente, na segunda quinzena de abril, com adubação de $50 \mathrm{~kg} \mathrm{ha}^{-1}$ de $\mathrm{P}_{2} \mathrm{O}_{5}$ e 50 $\mathrm{kg} \mathrm{ha}^{-1}$ de $\mathrm{K}_{2} \mathrm{O}$. A cultivar utilizada foi a IPR 85, 
com 60 sementes por metro linear e espaçamento entrelinhas de $0,17 \mathrm{~m}$. A adubação nitrogenada de cobertura, nas diferentes doses, ocorreu aos 30 dias após a semeadura do trigo, quando este se encontrava na fase de perfilhamento. A aplicação das diferentes doses foi realizada manualmente, próxima à linha de semeadura e na superfície do solo, tendo a ureia como fonte de nitrogênio. A aplicação das doses 120 e $150 \mathrm{~kg} \mathrm{ha}^{-1}$ de nitrogênio foram parceladas em duas vezes com o intuito de minimizar as perdas por volatilização, sendo a segunda aplicação realizada uma semana após a primeira.

Durante o período do experimento, não houve necessidade de aplicação de herbicidas, fungicidas ou inseticidas no manejo da cultura do trigo. A amostragem de folhas de trigo foi realizada no início do espigamento, sendo coletadas 30 folhas-bandeira por subparcela. Estas folhas foram secas em estufa com circulação forçada de ar a $65^{\circ} \mathrm{C}$, até peso constante e, após a secagem, foram moídas e submetidas à determinação dos teores de nitrogênio pelo método de Kjeldahl (MALAVOLTA; VITTI; OLIVEIRA, 1997).

$\mathrm{Na}$ colheita, determinou-se a altura das plantas de trigo, pela medida compreendida entre a superfície do solo e a inserção da folha bandeira, e o número de perfilhos produtivos por planta, com a amostragem de dez plantas por subparcela. As plantas presentes nas cinco linhas centrais da área útil da parcela foram cortadas manualmente e, posteriormente, trilhadas. Os grãos, após beneficiamento, tiveram sua umidade corrigida para $13 \%$ para as determinações de massa de mil grãos, peso hectolitro e produtividade. O peso hectolitro foi determinado em balança específica.

Os dados foram submetidos ao teste de normalidade de Lilliefors e ao teste F, ao nível de $5 \%$ de probabilidade. Os adubos verdes foram avaliados pela comparação das médias dos tratamentos pelo teste de Tukey, a 5\% de probabilidade, e o efeito das doses de nitrogênio em cobertura foi analisado por meio do ajuste de equações de regressão. Quando o teste $F$ foi significativo para a interação adubo verde $\mathrm{x}$ doses de nitrogênio, realizou-se o desdobramento da interação, por meio da análise de regressão das doses de nitrogênio em cada adubo verde. O software estatístico utilizado foi o Assistat, desenvolvido por Silva e Azevedo (2002).

\section{Resultados e Discussão}

A produção de massa seca da parte aérea da crotalária, aos 75 dias após a semeadura, foi significativamente superior ao das outras coberturas vegetais, refletindo em maior quantidade de nitrogênio acumulado, em $\mathrm{kg}$ $\mathrm{ha}^{-1}$ (Tabela 2). A baixa produção de massa seca da ervilhaca peluda possivelmente pode ser atribuída ao seu crescimento inicial lento e à época de manejo das coberturas, 75 dias após sua semeadura. Melhores resultados em produção de massa seca pela ervilhaca peluda foram encontrados por Martins e Rosa Júnior (2005) e Silva et al. (2006), que estudaram o cultivo de ervilhaca peluda como adubo verde na cultura do milho em Dourados-MS e relataram quantidades de massa seca acima de $3.000 \mathrm{~kg} \mathrm{ha}^{-1}$, aos 113 e 153 dias após a semeadura, respectivamente. A vegetação espontânea presente nas parcelas do tratamento-testemunha em pousio era composta principalmente por trapoeraba (Commelina benghalensis L.), amendoim bravo (Euphorbia heterophylla L.), capim carrapicho (Cenchrus echinatus L.), picão preto (Bidens pilosa L.) e capim braquiária (Brachiaria decumbens Stapf). 
Tabela 2. Massa seca (MS), teor de nitrogênio e quantidade acumulada deste nutriente ( $\mathrm{N}$ acumulado) na parte área das coberturas vegetais, e altura das plantas de trigo. Dourados - MS, 2007.

\begin{tabular}{llccc}
\hline & $\begin{array}{c}\text { MS } \\
\left(\mathbf{k g ~ h a}^{-1}\right)\end{array}$ & $\begin{array}{c}\text { Teor de } \mathbf{N} \\
\left(\mathbf{g ~ k g ~}^{-1} \mathbf{)}\right.\end{array}$ & $\begin{array}{c}\mathbf{N} \text { acumulado } \\
(\mathbf{k g ~ h a}\end{array}$ & $\begin{array}{c}\text { Altura } \\
\mathbf{( c m})\end{array}$ \\
\hline Crotalária & $12.020 \mathrm{a}$ & $32,6 \mathrm{a}$ & $391,9 \mathrm{a}$ & $62,2 \mathrm{a}$ \\
Ervilhaca & $621 \mathrm{~b}$ & $37,2 \mathrm{a}$ & $23,1 \mathrm{~b}$ & $60,2 \mathrm{ab}$ \\
Pousio & $176 \mathrm{~b}$ & $13,0 \mathrm{~b}$ & $2,3 \mathrm{c}$ & $57,5 \mathrm{~b}$ \\
DMS & 1.876 & 5,0 & 19,7 & 3,5 \\
CV $(\%)$ & 21,2 & 9,1 & 7,3 & 6,9 \\
\hline
\end{tabular}

Médias seguidas por letras diferentes em uma mesma coluna diferem entre si pelo teste de Tukey a 5\% de probabilidade.

Os teores de nitrogênio nas folhas de trigo no início do espigamento (Tabela 3) encontravamse adequados, segundo os padrões nutricionais estabelecidos por Raij et al. (1997). Ainda em relação aos teores médios de nitrogênio nas folhas de trigo, observou-se interação significativa $(\mathrm{p} \leq$ $0,01)$ entre adubos verdes e doses de nitrogênio em adubação de cobertura, sendo que as plantas de trigo cultivadas após a crotalária apresentaram maior teor de nitrogênio nas folhas do que as plantas cultivadas após a ervilhaca peluda ou após o tratamento-testemunha em pousio, em todas as doses de nitrogênio mineral estudadas (Tabela 3). Este resultado pode ser atribuído à maior produção de massa vegetal e ao maior aporte de nitrogênio acumulado na leguminosa (Tabela 2), que resultou em maiores teores do nutriente no solo. $\mathrm{O}$ teor de nitrogênio nas folhas de trigo aumentou de forma linear com o incremento da dose de nitrogênio aplicada em cobertura, em todas as coberturas vegetais estudadas (Figura 1a).

Figura 1. Teores de nitrogênio no tecido foliar das plantas de trigo (a) e altura de plantas (b), em função dos adubos verdes e das doses de nitrogênio em cobertura. Dourados - MS, 2007.
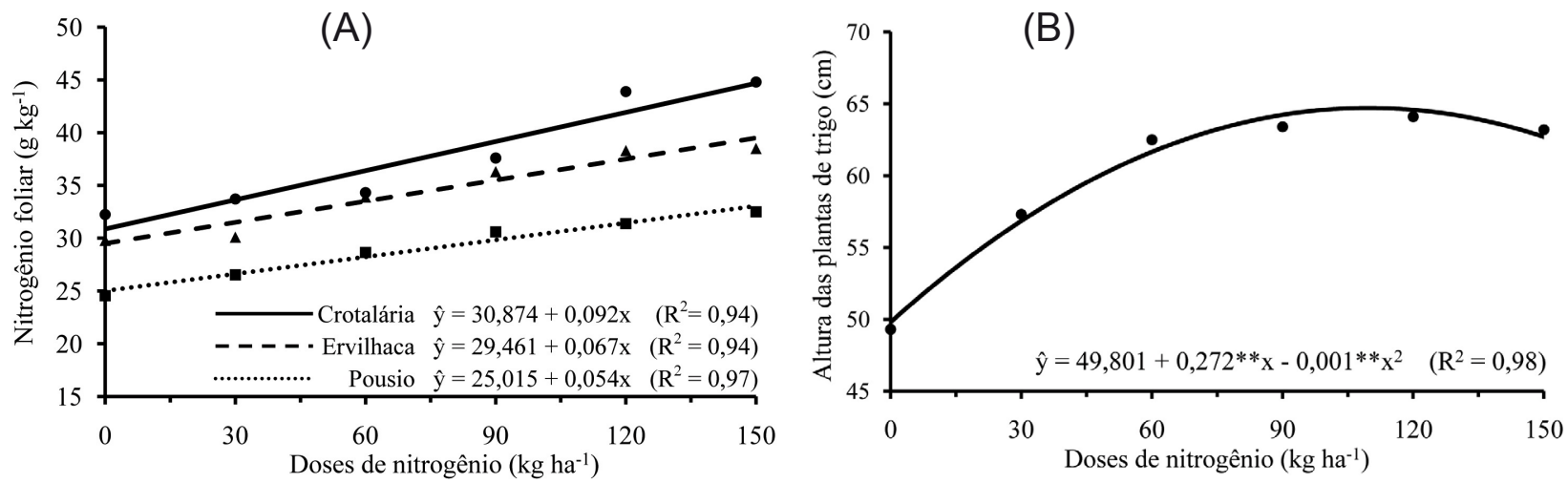
Tabela 3. Teores de nitrogênio nas folhas de trigo, em função dos adubos verdes e das doses de nitrogênio mineral em cobertura. Dourados - MS, 2007.

\begin{tabular}{lcccccc}
\hline Adubos & \multicolumn{7}{c}{ Doses de $\mathbf{~}\left(\mathbf{k g ~ h a}^{-1}\right)$} \\
\cline { 2 - 7 } verdes & $\mathbf{0}$ & $\mathbf{3 0}$ & $\mathbf{6 0}$ & $\mathbf{9 0}$ & $\mathbf{1 2 0}$ & $\mathbf{1 5 0}$ \\
\hline Crotalária & $33,0 \mathrm{a}$ & $33,7 \mathrm{a}$ & $34,3 \mathrm{a}$ & $43,4 \mathrm{a}$ & $44,9 \mathrm{a}$ & $43,7 \mathrm{a}$ \\
Ervilhaca & $29,8 \mathrm{~b}$ & $30,1 \mathrm{~b}$ & $31,2 \mathrm{~b}$ & $36,3 \mathrm{~b}$ & $38,3 \mathrm{~b}$ & $38,5 \mathrm{~b}$ \\
Pousio & $24,6 \mathrm{c}$ & $26,5 \mathrm{c}$ & $28,1 \mathrm{~b}$ & $30,6 \mathrm{c}$ & $31,4 \mathrm{c}$ & $32,5 \mathrm{c}$ \\
\hline
\end{tabular}

Médias seguidas por letras diferentes em uma mesma coluna diferem entre si pelo teste de Tukey a $5 \%$ de probabilidade. $\mathrm{DMS}=2,9$ e CV $(\%)=5,7$.

Comparando-se a altura das plantas de trigo dentro de cada cobertura vegetal, observou-se que as plantas de trigo cultivadas após a crotalária eram maiores que as cultivadas após o pousio, e as plantas de trigo cultivadas após a ervilha peluda apresentaram comportamento intermediário às cultivadas após crotalária e pousio. (Tabela 2). Resultados semelhantes foram encontrados por Santos et al. (2006), que avaliaram os efeitos de práticas culturais sobre o desempenho agronômico das plantas de trigo e observaram que as plantas de trigo eram significativamente maiores quando cultivadas em sistemas de rotação de culturas com leguminosas. O modelo de regressão que melhor se ajustou aos resultados de altura das plantas de trigo em função das doses de nitrogênio em cobertura foi o quadrático, com o ponto de máxima da equação $(68,3 \mathrm{~cm})$ na dose de $136 \mathrm{~kg} \mathrm{ha}^{-1}$ de nitrogênio (Figura 1b). Estes resultados diferem dos encontrados por Teixeira Filho et al. (2007) que, estudando cinco doses de nitrogênio em adubação de cobertura, constataram que não houve efeito das doses de nitrogênio sobre a altura das plantas de trigo, possivelmente devido à aplicação de nitrogênio na semeadura e à realização da adubação de cobertura em um estágio mais tardio da cultura.

Observou-se maior perfilhamento da cultura do trigo quando o mesmo foi cultivado após a crotalária (Tabela 4) e, por meio da análise de regressão das respostas às diferentes doses de nitrogênio na adubação de cobertura, podese concluir que o modelo quadrático foi o que mostrou melhor ajuste aos dados, alcançando o valor máximo $(3,47)$ na dose de $110 \mathrm{~kg} \mathrm{ha}^{-1}$ de nitrogênio (Figura 2a). Em estudo realizado por Zagonel et al. (2002), observou-se também o aumento do número de perfilhos produtivos por planta com o acréscimo de nitrogênio em cobertura, até a dose de $105 \mathrm{~kg} \mathrm{ha}^{-1}$. O número de perfilhos produtivos por planta está diretamente associado à produção de espigas por unidade de área e, consequentemente, com a produtividade do trigo. Um dos motivos da baixa produtividade média das lavouras de trigo no Brasil é a pequena participação dos perfilhos na formação do rendimento final (ALMEIDA et al., 2002). Sendo assim, a emissão, o desenvolvimento e a sobrevivência dos perfilhos são importantes, pois estas estruturas fazem parte dos componentes de desempenho agronômico e são também supridoras de assimilados ao colmo principal. 
Figura 2. Número de perfilhos produtivos por planta (a) e peso hectolitro dos grãos de trigo (b), em função das doses de nitrogênio em cobertura. Dourados - MS, 2007.

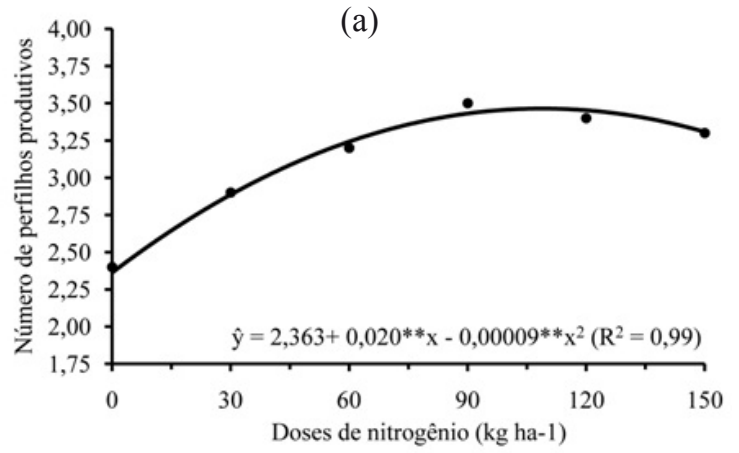

(b)



Tabela 4. Número de perfilhos produtivos, massa de mil grãos e peso hectolitro, em função dos adubos verdes. Dourados - MS, 2007.

\begin{tabular}{|c|c|c|c|}
\hline & $\begin{array}{c}\text { Número de } \\
\text { perfilhos }\end{array}$ & $\begin{array}{c}\text { Massa de } \\
\text { mil grãos (g) }\end{array}$ & $\begin{array}{c}\text { Peso hectolitro } \\
\left(\mathrm{kg} \mathrm{hL}^{-1}\right)\end{array}$ \\
\hline Crotalária & $3,5 \mathrm{a}$ & $33,7 \mathrm{a}$ & $76,6 \mathrm{a}$ \\
\hline Ervilhaca & $3,0 \mathrm{~b}$ & $33,4 \mathrm{a}$ & $74,7 \mathrm{ab}$ \\
\hline Pousio & $2,9 \mathrm{~b}$ & $33,2 \mathrm{a}$ & $72,4 \mathrm{~b}$ \\
\hline DMS & 0,3 & 1,8 & 2,2 \\
\hline CV $(\%)$ & 10,4 & 6,2 & 14,6 \\
\hline
\end{tabular}

Médias seguidas por letras diferentes em uma mesma coluna diferem entre si pelo teste de Tukey a 5\% de probabilidade.

Não houve efeito dos adubos verdes ou das doses de nitrogênio mineral em adubação de cobertura na medida da massa de mil grãos (Tabela 4). Estes resultados corroboram com os obtidos por Braz et al. (2006), que não observaram diferença estatística na massa de mil grãos do trigo cultivado em sistema plantio direto em sucessão a diferentes culturas de cobertura e diferem dos resultados relatados por Teixeira Filho et al. (2007), que encontraram efeito significativo de diferentes doses de nitrogênio em cobertura na massa de cem grãos do trigo. Entretanto, o aumento da massa de grãos, normalmente associado à maior disponibilidade de nitrogênio durante as fases de floração e início do 
enchimento de grãos, não garante necessariamente maior produtividade da cultura do trigo (DIDONET et al., 2000).

Os valores de peso hectolitro obtidos quando o trigo foi semeado após os adubos verdes foram os que mais se aproximaram do peso hectolitro-padrão utilizado na comercialização, que é de $78 \mathrm{~kg} \mathrm{hL}^{-1}$ (Tabela 4). O ajuste da equação quadrática para as doses de nitrogênio em cobertura (Figura 2b) permitiu determinar o ponto de máxima resposta $\left(77,7 \mathrm{~kg} \mathrm{hL}^{-1}\right)$ na dose de $114 \mathrm{~kg} \mathrm{ha}^{-1}$ de nitrogênio. $\mathrm{O}$ peso hectolitro é utilizado na classificação e comercialização do trigo, e é influenciado pela uniformidade, forma, densidade e tamanho do grão, além do conteúdo de matérias estranhas e grãos quebrados da amostra. Desta forma, quanto maior o peso hectolitro, maior o rendimento de farinha e, portanto, maior a qualidade do produto. Estes resultados ratificam os encontrados por Santos et al. (2006), que observaram que a rotação de culturas do trigo com leguminosas promove ganhos significativos no peso hectolitro.

A interação entre adubos verdes e doses de nitrogênio em adubação de cobertura foi significativa $(\mathrm{p} \leq 0,01)$ para a produtividade da cultura do trigo; e as maiores produtividades foram determinadas quando o trigo foi cultivado após a crotalária, na maioria das doses (Tabela 5). Estes resultados corroboram com os relatados por Braz et al. (2006), que observam que, para uma mesma produtividade do trigo, a necessidade de adubação mineral nitrogenada é menor quando o mesmo é cultivado após leguminosas. Observou-se resposta quadrática da produtividade do trigo ao incremento da dose de nitrogênio mineral em cobertura, nas três coberturas vegetais testadas (Figura 3). Por meio da equação de regressão obtida para o manejo em pousio e da produtividade do trigo cultivado após a crotalária e sem aplicação de nitrogênio mineral, pode-se inferir que a equivalência em nitrogênio mineral fornecido pela crotalária foi de $33,22 \mathrm{~kg}$ $\mathrm{ha}^{-1}$ de nitrogênio. A média geral de produtividade do trigo no experimento foi $2.870 \mathrm{~kg} \mathrm{ha}^{-1}$, superior aos $1.500 \mathrm{~kg} \mathrm{ha}^{-1}$ verificados para Dourados - MS, e aos $1.260 \mathrm{~kg} \mathrm{ha}^{-1}$, observados no Estado de Mato Grosso do Sul no ano de 200 (IBGE, 2007) 7. A maior produtividade $\left(3.755 \mathrm{~kg} \mathrm{ha}^{-1}\right)$ foi determinada nas plantas de trigo tendo a crotalária como adubo verde e com a dose de $120 \mathrm{~kg} \mathrm{ha}^{-1}$ de nitrogênio em adubação de cobertura. Efeitos significativos de doses de nitrogênio em adubação de cobertura na produtividade da cultura do trigo também foram encontrados por Da Ros et al. (2003) e Teixeira Filho et al. (2007).

Figura 3. Produtividade da cultura do trigo $\left(\mathrm{kg} \mathrm{ha}^{-1}\right)$, em função dos adubos verdes e das doses de nitrogênio em cobertura. Dourados - MS, 2007.

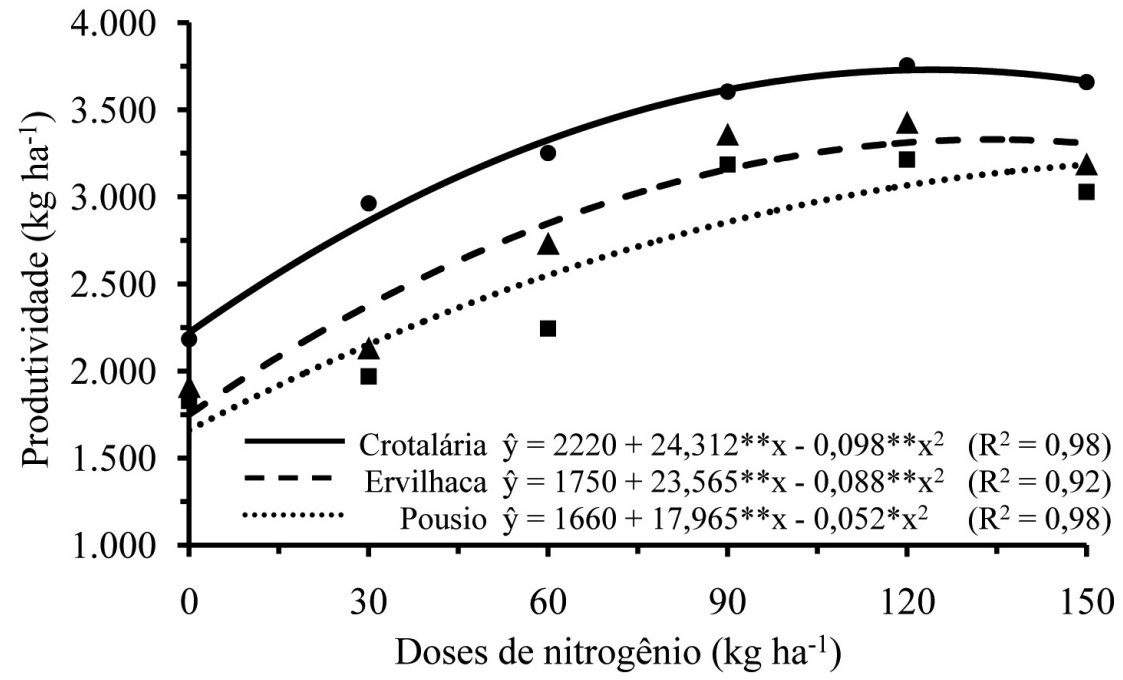


Tabela 5. Produtividade $\left(\mathrm{kg} \mathrm{ha}^{-1}\right)$ da cultura do trigo, em função dos adubos verdes e das doses de nitrogênio mineral em cobertura. Dourados - MS, 2007.

\begin{tabular}{lcccccc}
\hline $\begin{array}{l}\text { Adubos } \\
\text { verdes }\end{array}$ & $\mathbf{0}$ & $\mathbf{3 0}$ & $\mathbf{6 0}$ & $\mathbf{9 0}$ & $\mathbf{1 2 0}$ & $\mathbf{1 5 0}$ \\
\hline Crotalária & $2.183 \mathrm{a}$ & $2.963 \mathrm{a}$ & $3.252 \mathrm{a}$ & $3.604 \mathrm{a}$ & $3.755 \mathrm{a}$ & $3.659 \mathrm{a}$ \\
Ervilhaca & $1.821 \mathrm{~b}$ & $2.133 \mathrm{~b}$ & $2.733 \mathrm{~b}$ & $3.253 \mathrm{~b}$ & $3.428 \mathrm{ab}$ & $3.189 \mathrm{~b}$ \\
Pousio & $1.808 \mathrm{~b}$ & $1.969 \mathrm{~b}$ & $2.244 \mathrm{c}$ & $3.085 \mathrm{~b}$ & $3.214 \mathrm{~b}$ & $3.028 \mathrm{~b}$ \\
\hline
\end{tabular}

Médias seguidas por letras diferentes em uma mesma coluna diferem entre si pelo teste de Tukey a $5 \%$ de probabilidade. $\mathrm{DMS}=350$ e $\mathrm{CV}(\%)=8,9$.

Ressalta-se que, embora se tenha observado efeito do cultivo de crotalária já na safra imediatamente seguinte, em trabalho realizado por Araújo et al. (2005), observou-se que apenas $14 \%$ do nitrogênio da crotalária foi recuperado nas plantas de trigo, independentemente da aplicação ou não de ureia. Estes mesmos autores verificaram que cerca de $80 \%$ do nitrogênio da crotalária permaneceu no solo por causa da lenta mineralização do nutriente presente na leguminosa, podendo ser aproveitado por outras culturas em sucessão.

A menor produtividade do trigo cultivado após a ervilhaca peluda, se comparada com a do trigo após crotalária, está relacionada com a menor produção de massa seca e com a menor quantidade de nitrogênio acumulado pela leguminosa no momento do seu manejo (Tabela 2). Resultados semelhantes foram encontrados por Argenta et al. (1999) na cultura do milho, que concluíram que quando a ervilhaca não se desenvolve bem, o suprimento de nitrogênio para o milho semeado em sucessão pode ficar abaixo do esperado.

\section{Conclusões}

Com base nos resultados obtidos e nas condições em que o experimento foi realizado pode-se concluir que a resposta do trigo a aplicação de nitrogênio mineral é variável em função da cultura antecessora e que o cultivo de crotalária antecedendo à semeadura do trigo promove acréscimos significativos na produtividade da cultura.

\section{Agradecimentos}

À Fundação de Apoio e de Desenvolvimento do Ensino, Ciência e Tecnologia do Estado de Mato Grosso do Sul (Fundect), pela concessão da bolsa de estudos e pelo apoio financeiro.

\section{Referências}

AITA, C.; BASSO, C. J.; CERETA, C. A.; GONÇALVES, C. N.; DA ROS, C. O. Plantas de cobertura de solo como fonte de nitrogênio ao milho. Revista Brasileira de Ciência do Solo, Viçosa, v. 25, n. 1, p. 157-165, 2001.

ALMEIDA, M. L.; SANGOI, L.; TRENTIN, P. S.; GÁLIO, J. Cultivares de trigo respondem diferentemente à qualidade da luz quanto à emissão de afilhos e acumulação de massa seca. Ciência Rural, Santa Maria, v. 32 , n. 3 , p. $377-383,2002$

AMABILE, R. F.; FANCELLI, A. L.; CARVALHO, A. M. de. Comportamento de espécies de adubos verdes em diferentes épocas de semeadura e espaçamentos na região dos cerrados. Pesquisa Agropecuária Brasileira, Brasília, v. 35, n. 1, p. 47-54, 2000.

AMADO, T. J. C.; MIELNICZUK, J.; FERNANDES, S. B. V. Leguminosas e adubação mineral como fontes de nitrogênio para o milho em sistemas de preparo do solo. Revista Brasileira de Ciência do Solo, Viçosa, v. 24, n. 1, p. 179-189, 2000.

ARAÚJO, A. F.; TEIXEIRA, G. M.; CAMPOS, A. X.; SILVA, F. C.; AMBROSANO, E. J.; TRIVELIN, P. C. O. Utilização de nitrogênio pelo trigo cultivado em solo fertilizado com adubo verde (Crotalaria juncea) e/ou uréia. Ciência Rural, Santa Maria, v. 35, n. 2, p. 284-289, 2005.

ARF, O.; SILVA, L. S.; BUZETTI, S.; ALVES, M. C.; SÁ, M. E.; RODRIGUES, R. A. F.; HERNANDEZ, F. 
B. T. Efeitos na cultura do trigo da rotação com o milho e adubos verdes, na presença e na ausência de adubação nitrogenada. Bragantia, Campinas, v. 58, n. 2, p. 323334, 1999.

ARGENTA, G.; SILVA, P. R. F.; RIZZARDI, M. A.; BARUFFI, M. J.; BEHEREGARAY NETO, V. Manejo do nitrogênio no milho em semeadura direta em sucessão a espécies de cobertura de solo no inverno e em dois locais. I - Efeito sobre a absorção de N. Ciência Rural, Santa Maria, v. 29, n. 4, p. 577-586, 1999.

BOLOGNA, I. R.; FARONI, C. E.; LANGE, A.; TRIVELIN, P. C. Perda de nitrogênio pela parte aérea de plantas de trigo. Ciência Rural, Santa Maria, v. 36, n. 4, p. 1106-1111, 2006.

BRAZ, A. J. B. P.; SILVEIRA, P. M.; KLIEMANN, H. J.; ZIMMERMANN, F. J. P. Adubação nitrogenada em cobertura na cultura do trigo em sistema plantio direto após diferentes culturas. Ciência e Agrotecnologia, Lavras, v. 30, n. 2, p. 193-198, 2006.

BREDEMEIER, C.; MUNDSTOCK, C. M. Estádios fenológicos do trigo para a adubação nitrogenada em cobertura. Revista Brasileira de Ciência do Solo, Viçosa, v. 25 , n. 2 , p. $317-323,2001$.

CLAESSEN, M. E. C. (Org.). Manual de métodos de análise de solo. 2. ed. Rio de Janeiro: Embrapa/CNPS, 1997. 212 p. (Documentos, 1).

DA ROS, C. O.; SALET, R. L.; PORN, R. L.; MACHADO, J. N. C. Disponibilidade de nitrogênio e produtividade de milho e trigo com diferentes métodos de adubação nitrogenada no sistema plantio direto. Ciência Rural, Santa Maria, v. 33, n. 5, p. 799-804, 2003.

DIDONET, A. D.; RODRIGUES, O.; LIMA, O. S.; CANDATEN, A. A. Realocação de nitrogênio e de biomassa para os grãos, em trigo submetido à inoculação de Azospirillum. Pesquisa Agropecuária Brasileira, Brasília, v. 35, n. 2, p. 401-411, 2000.

EMPRESA BRASILEIRA DE PESQUISA AGROPECUÁRIA - EMBRAPA. Centro Nacional de Pesquisa de Solos. Sistema brasileiro de classificação de solos. 2. ed. Rio de Janeiro: Embrapa, 2006. 306 p.

HOOD, R. C. Evaluation of a new approach to the nitrogen-15 isotope dilution technique, to estimate crop $\mathrm{N}$ uptake from organic residues in the field. Biology and Fertility of Soils, Berlin, v. 34, n. 3, p. 156-161, 2001.

INSTITUTO BRASILEIRO DE GEOGRAFIA E ESTATÍSTICA - IBGE. Levantamento sistemático da produção agrícola. Campo Grande: IBGE, 2007.

MALAVOLTA, E.; VITTI, G. C.; OLIVEIRA, S. A. Avaliação do estado nutricional de plantas: princípios e aplicações. 2. ed. Piracicaba: Potafos, 1997. p. 115-230.

MARRERO, D. F.; DELGADO, L. E. P.; IANEZ, N. C.; CALERO, C. M; RODRIGUEZ, M. L. Cubierta vegetal con Teramnus labialis en plantaciones citrícolas: efectos sobre algunas propiedades físicas del suelo. Semina: Ciências Agrárias, Londrina, v. 30, p. 1073-1082, 2009. Suplemento 1.

MARTINS, R. M. G.; ROSA JÚNIOR, E. J. Culturas antecessoras influenciando a cultura de milho e os atributos do solo no sistema de plantio direto. Acta Scientiarum Agronomy, Maringá, v. 27, n. 2, p. 225-232, 2005.

RAIJ, B. van; CANTARELLA, H.; QUAGGIO, J. A.; FURLANI, A. M. C. (Ed.). Recomendações de adubação e calagem para o Estado de São Paulo. 2. ed. Campinas, IAC, 1997. 285 p. (Boletim técnico, 100).

SANTOS, H. P.; LHAMBY, J. C. B.; SPERA, S. T.; ÁVILA, A. Efeito de práticas culturais sobre o rendimento e outras características agronômicas de trigo. Bragantia, Campinas, v. 65, n. 4, p. 669-677, 2006.

SILVA, D. A.; VITORINO, A. C. T.; SOUZA, L. C. F.; GONÇAlVES, M. C.; ROSCOE, R. Culturas antecessoras e adubação nitrogenada na cultura do milho em sistema plantio direto. Revista Brasileira de Milho Sorgo, Sete Lagoas, v. 5, n. 1, p. 75-88, 2006.

SILVA, F. A. S. E.; AZEVEDO, C. A. V. Versão do programa computacional Assistat para o sistema operacional Windows. Revista Brasileira de Produtos Agroindustriais, Campina Grande, v. 4, n. 1, p. 71-78, 2002.

SILVA, M. G.; ARF, O.; ALVES, M. C.; BUZETTI, S. Sucessão de culturas e sua influência nas propriedades físicas do solo e na produtividade do feijoeiro de inverno irrigado, em diferentes sistemas de manejo do solo. Bragantia, Campinas, v. 67, n. 2, p. 335-347, 2008.

TEIXEIRA FILHO, M. C. M.; BUZETTI, S.; ALVAREZ, R. C. F.; FREITAS, J. G.; ARF, O.; SÁ, M. E. Resposta de cultivares de trigo irrigados por aspersão ao nitrogênio em cobertura na região do Cerrado. Acta Scientiarum Agronomy, Maringá, v. 29, n. 3, p. 421-425, 2007.

ZAGONEL, J.; VENÂNCIO, W. S.; KUNZ, R. P.; TANAMATI, H. Doses de nitrogênio e densidades de plantas com e sem um regulador de crescimento afetando o trigo, cultivar OR-1. Ciência Rural, Santa Maria, v. 32, n. 1, p. 25-29, 2002. 